\title{
Editorial
}

\section{A legacy to cherish}

\section{Eduardo Villanueva-Mansilla}

\author{
Co-Editor in Chief, the Journal of Community \\ Informatics. \\ evillan@pucp.pe
}

This, the first issue of the twelfth volume of the Journal of Community Informatics, signals a change. Michael Gurstein, founder and editor-in-chief for all these years, has left the (metaphorical) building. He shall keep contributing to the Journal, as an emeritus editor; and his stewardship of this most collective enterprise has certainly left a mark to be appreciated and thanked.

I have been asked to assume the role of Editor in Chief, a job made easier by Michael's continuous presence in his new emeritus position; and the coming co-editorship of Susan O’Donnell, who will take that role starting January 1st, 2017.

A minimal introduction is in order. I am currently an Associate Professor in the Department of Communications of the Pontificia Universidad Católica del Perú. My participation in this particular community of researchers, scholars, professionals, practitioners, activists and promoters has been mostly as an observer and academic commentator, trying to connect the concerns and interests of the larger field with those of Latin American scholars and practitioners, mostly from the communication studies area, but also from the social sciences and engineering / computing perspectives.

Among other positions, I am currently coordinator of the Working Group on Communication, Technology and Development of the Latin American Association of Communication Researchers (ALAIC). I have had the chance to meet the larger community involved in this Journal in conferences, private exchanges and through the work of the Journal, in which I was involved back in the late Noughties. Having been invited by Michael to take over the editorship, I am both quite enthused and motivated with the challenge. The Journal has a legacy to cherish. I will not get into figures, but it is evident that with all the limitations an independent, open access journal has in the current environment, a lot has been achieved; this is thanks to the help of all those involved in the whole process of running, collaborating and finally, publishing the Journal. 
As any change of stewardship should be an opportunity for renewal, while keeping the good things already there, this new volume offers two differences to the current, one perhaps cosmetic, the other what I think could be the beginning of a new dialogue.

1. As you can see, the Journal has changed the publishing style. It will now be available as PDF files, with page numbering, section indications and some other of the trappings that many of us in academia are familiar with. Some other additions, like a Digital Object Identifier for each article, will demand further work, but these are on the agenda. In a settled environment, as the academic journals are in for the most part, these additions only provide for a more contemporary look and facilitation of referencing and archiving, something of use to many of our authors, from academia and otherwise.

2. A new section has been added. Called Essays: on communities, it looks toward a dialogue on what a community is, should be or may become, throughout the world, including emerging definitions of community. A call for anyone interested to collaborate in this debate, from any perspective, is now open. Submissions will not be peer-reviewed, but just reviewed by the editor, and published as fast as possible, to contribute to a necessary dialogue.

In the coming months, while new special editions are to be published, there will be an opportunity to think about the Journal, its future both immediate and long-term, and the way the community around it should participate, on both the ciresearchers and joci mail lists. We need to start thinking about the future right away: not just in terms of issues to call and papers to submit, but foremost as emerging subjects to be covered, running debates to be promoted, new audiences to be reached and people that should participate. The Journal, global in its nature, has a wide variety of countries and professional backgrounds represented; this should increase, and as far as possible increase geographical representation as much as thematic coverage. I will strive to promote as much as possible such intentions, but I request the community's help to achieve these goals. While English will remain the language of publication, any suggestions on how to widen linguistic representation is most welcome.

I will hold the position of Editor in Chief for four years, from 2016 to the end of 2019, at which time a new editor should be appointed if the Journal is still relevant and cherished by all the members of this worldwide community on communities. I am fully confident that it will still be, hopefully as much as Michael is leaving it right now. Perhaps we can achieve not just a regularly-published, better looking Journal: while keeping its openness, widening its international presence both in contributions and readership, and keeping with the variety and diversity of subjects that constitute its areas of interest, we, all together, may find ourselves still providing at least part of the collective solutions that communities, through ICT / Informatics / computers / digital media, all around our common home called the Earth, require and demand for their lives. In the end, that is what all this is about. 